\title{
The Cause of Frequent Infection and Persistent Cough Is Accessories Cardiac Bronc
}

\author{
Yasemin Behram Kandemir \\ Harran University, Department of Anatomy, Faculty of Medicine, Sanliurfa/Turkey \\ ORCID 0000-0002-6490-9155 \\ Serif Kurtulus \\ Harran University, Department of Chest Diseases, Faculty of Medicine, Sanliurfa/Turkey \\ ORCID 0000-0002-1082-3700
}

\begin{abstract}
Anatomical variations or tracheobronchial anomaly (TBA) have been rarely reported in the literature. Different types of anatomical variations may be present, but accessory cardiac bronchus may be rare and may be the cause of persistent cough or lower respiratory tract infections. Two patients who are admitted to the Department of Chest Diseases of Harran University Faculty of Medicine, for more than a decade with complaints of cough and frequent infection, were found to have an accessory cardiac bronchus which is laterally on the right main bronchus, karena level, except for the upper lobe bronchus, by chest computed tomography and bronchoscopy. We believe that the knowledge of tracheal variations seen in the anatomy of the lungs may be important in surgical procedures such as lobectotomy and segmentectomy in the lungs, and may be useful in the evaluation of long-term cough or frequent recurrent lower respiratory tract infections.
\end{abstract}

Keywords; Accessory cardiac bronchus, lung, variation

Special Issue of Health Sciences

DOI: $10.7176 / \mathrm{JSTR} / 6-03-35$

\section{Sık Enfeksiyon ve İnatçı Öksürük Nedeni Olarak Aksesuar Kardiyak Bronş}

\begin{abstract}
Özet
Anatomik varyasyonlar veya trakeobronşial anomali (TBA) literatürde çok az bildirilmiştir. Farklı tipte anatomik varyasyonlar olabileceği gibi nadir olarak aksesuar kardiyak bronş saptanabilir ve bu kardiyak bronş inatçı öksürük veya alt solunum yolu enfeksiyonlarının nedeni olabilir. Harran Üniversitesi Tıp Fakültesi Gögüs Hastalıkları Anabilim Dalı'na on yıldan fazla devam eden öksürük ve sık enfeksiyon şikayetleri ile başvuran iki hastanın, toraks bilgisayarlı tomografi ve bronkoskopi sonrasında, sağ ana bronş karena seviyesinde laterale doğru olan üst lob bronşu dışında aksesuar kardiyak bronş izlendi. Akciğerler anatomisinde görülen trakeal varyasyonların bilinmesinin, akciğerlere yapılan lobektotimi ve segmentektomi gibi cerrahi işlemlerde önemli olabileceği gibi, uzun süren öksürük veya sık tekrarlayan alt solunum yolu enfeksiyonlarının sağlıklı değerlendirilmesinde faydalı olabileceği kanaatindeyiz.
\end{abstract}

Anahtar Kelimeler: Aksesuar kardiyak bronş, akciğer, varyasyon

\section{GÍRİŞ}

Geçmiş yıllarda \%1-12 oranında görülen trakeobronşial anomali ya da anatomik varyasyonlar (TBA), çok değişik şekillerde olabileceği gibi nadir olarak, akciğerin temel gelişimsel bronşial anomalisinden olan, aksesuar kardiyak bronş şeklinde saptanabilir ve inatçı öksürük nedeni olabilir $(1,2)$ 


\section{AKSESUAR KARDIYYAK BRONŞ}

Aksesuar kardiyak bronş ilk kez Brock tarafindan tanımlanan, toplumda \% 0. 07-0. 5 oranında rastlanan, normal bronş yapısına ek olarak görülen fazla sayıdaki anormal bir bronştur. Varyasyonel olan bu bronş, \%86 vakada intermediate bronşun medialinden, \% 14 vakada ise sağ ana bronştan,sağ üst lob bronşunun çıktığ yerin tam karşı seviyesinden çıkar $(3,4)$. Aksesuar kardiyak bronş nadir olarak dallanmalar göstersede $\% 70$ oranında kör bir divertikül gibi sonlanır (5).

2.1.Olgu 1: 33 yaşında, mülteci kadın hasta, on yıldan beri devam eden öksürük ve son on gün hemoptizi ve ateş şikayeti ile kliniğe başvurdu. Çekilen tomografisinde sağ akciğerde konsolide alanlar izlendi. Hastaya tüberküloz ön tanısı ile bronkoskopi planlandı. Yapılan bronkoskopide sağ ana bronş karena seviyesinde laterale doğru olan üst lob bronşu dışında aksesuar cardiyak bronş izlendi. Hastada lavaj ARB (Aside Dirençli Bakteri) (-) sonuçlandı. Ampicid tedavisine klinik-radyolojik yanıt alınan hasta pnemoni tanısı ile eksterne edildi (Şekil 1).

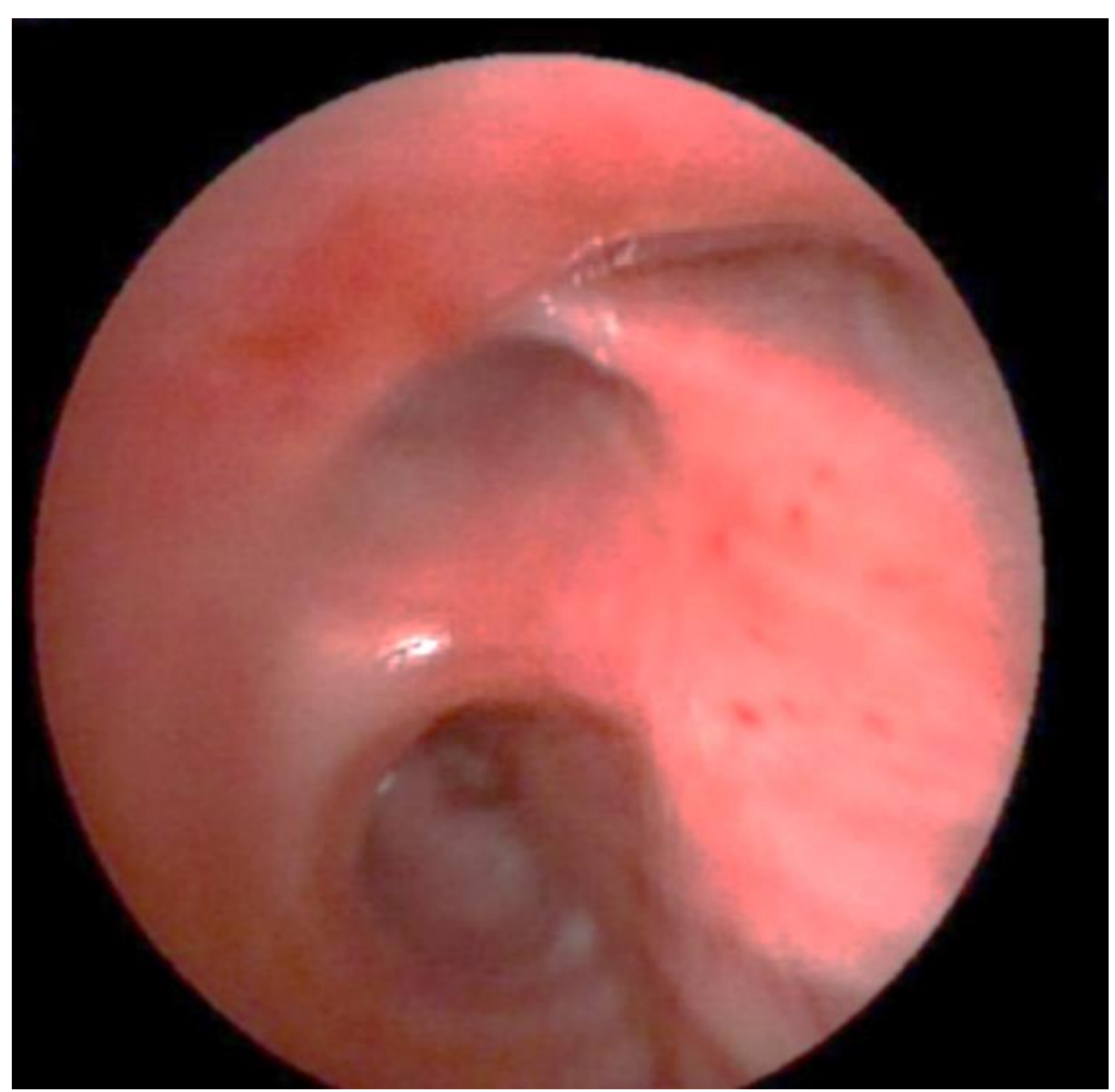

Şekil 1. Sağ ana bronş karena seviyesinde laterale doğru olan üst lob bronşu dışında aksesuar kardiyak bronş 
2.2. Olgu 2: 38 yaşında erkek hasta çocukluk döneminden beri ara ara öksürük ve son bir haftadır devam eden kanlı balgam şikayeti ile acil polikliniğine başvurdu. Geçirilmiş akciğer tüberküloz öyküsü mevcuttu. Çekilen akciğer grafide bilateral infilitrasyon ve sağ akciğerde volüm kaybı izlendi. Hastaya çekilen toraks bt'de, sağ akciğerde konsolide alanlar ve kavitasyon tespit edildi. Hastaya tüberküloz(?), Pnemoni (?), Akciğer malinite (?) ön tanılarıyla bronkoskopi planlandı, yapılan bronkoskopide sağ akciğer ana karena lateralinde aksesuar kardiyak bronş izlendi. Lavaj ARB (Aside Dirençli Bakteri) (-) olan hastanın sekel akciğer ve pnemoni tanısı ile tedavisi düzenlendi. Ampicid tedavisine klinikradyolojik-laburatuvar yanıt alınan hasta pnemoni tanısı ile eksterne edildi (Şekil 2).

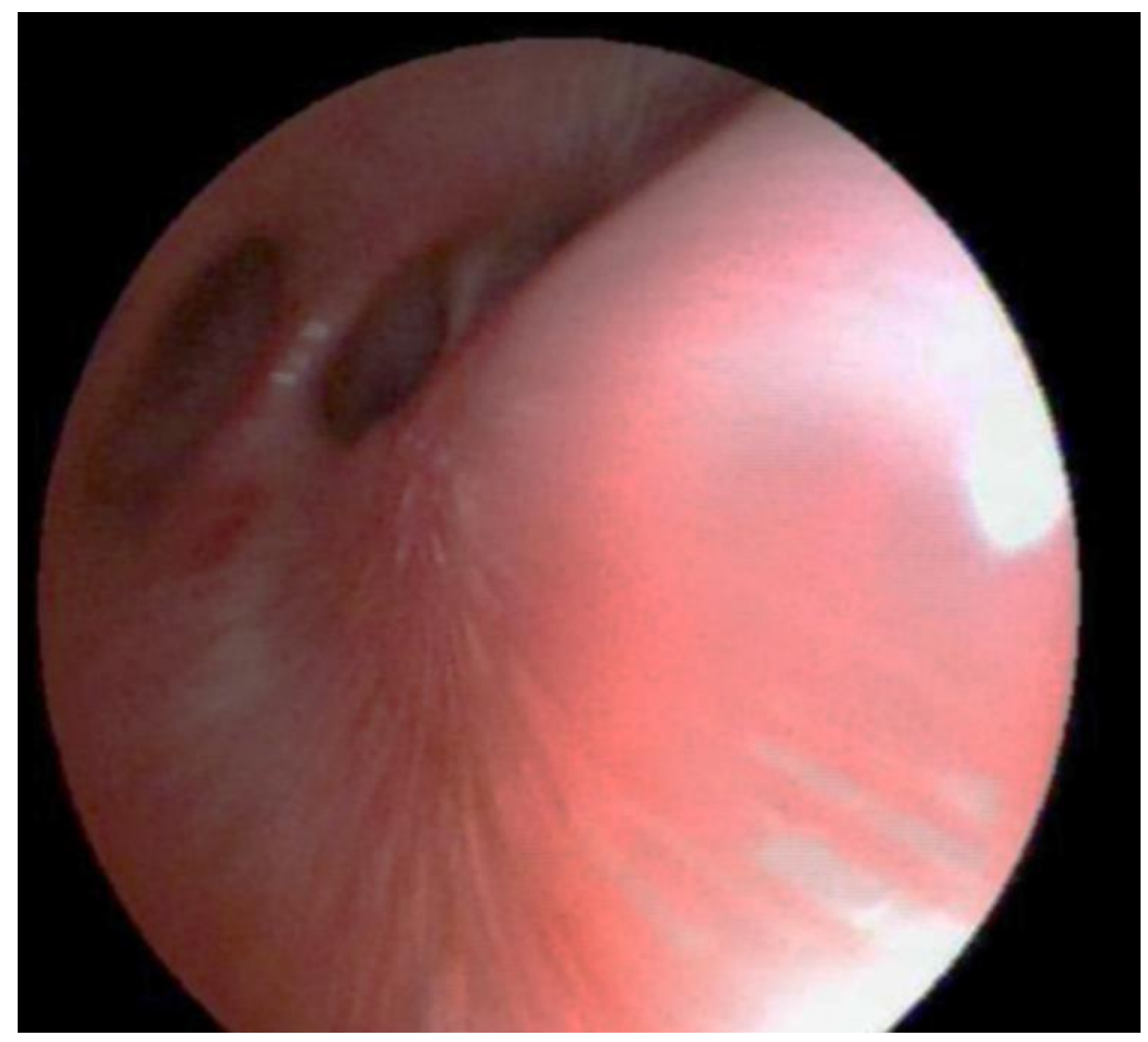

Şekil 2. Sağ akciğer ana karena lateralinde aksesuar kardiyak bronş

\section{Tartışma}

Trakeobronşial ağacın genellikle her hangi bir semptoma neden olmayan nadir görülen konjenital bir anomalisi olan aksesuar kardiyak bronş, sıklıkla akciğer radyografilerinde görülmez, rastlantısal olarak bronkografi, endoskopik bronkoskopi ya da BT ile saptanır.Bununla birlikte, bronşiyal anatomi en iyi "cross sectional", multiplanar rekonstrüksiyon ve üç boyutlu rekonstrüksiyon yöntemleriyle gösterilebilir (6). Aksesar kardiyak bronş, sağ ana bronş veya ara bronştan köken alan, genellikle üst lob bronşu karşısından trakeal duvardan köken alan, mediale doğru ve ara bronşa paralel uzanım gösteren anatomik varyasyondur (7). Aksesuar kardiyak bronş perikardiuma doğru ilerleyerek kaudalde azigoözefagial çıkmaz komşuluğunda intermedial bronşa parelel 1-5 cmlik koni şeklinde bir lobulusa dönüşmekle birlikte genelde kör olarak sonlanan bir yapıdır. Bu distaldeki lobulus, işlevini kaybetmiş bronşiolar parankimal doku, kistik dejenerasyon ya da havalanan bir parankim ile sonlanan küçük bronşiol dizilerinden oluşmakla birlikte trakeal bronş gibi diğer anatomik varyantlarının aksine, daima aksesuar bir bronştur (8).

Tüm bronşial anomaliler genellikle asemptomatik olmakla birlikte, drenaj yetersizliğinde ve ilave diğer anomaliler varlığında solunum sıkıntısıne sebeb olabilir. Literatürde, bütün aberan bronşların lokal infeksiyon, inatçı öksürük, stridor, özellikle çocuklarda daha sık gözlenen akut solunum sıkıntısı ve hemoptizi gibi durumlara yol açtığı bildirilmiştir. Bronşektazi, atelektazi ve özellikle üst loblarda görülen amfizem, kistik akciğer malformasyonları birlikte olabilirler (9-12). 
Her ne kadar literatürde büyük serilere sahip olan bir çalışmada erişkin bronşiyal anomalilere sahip olan hastaların hemen hepsi asemptomatik olsa da çocukluk yaş grubundaki hastalarda ve çoğunlukla da sol taraf bronşial anomaliler semptomatik seyrettiği bildirilsede $(12,13)$ bizim sunduğumuz olgularda uzun yıllardır devam eden inatçı bir öksürük mevcuttu ayrıca sunduğumuz olguların ikisinde de sağ tarafta aksesuar kardiyak bronş bulunmaktaydı.

Fiberoptik bronkoskopi, bronkoalveoler lavaj, biyopsi, endobronşiyal tedavi gibi işlemlerin yapılması sırasında çeşitli bronşiyal anomalilerin olabileceğinin bilinmesi, göğüs hastalıkları hekimine büyük katkılar sağlayabilir. Yine bir göğüs cerrahı için akciğer rezeksiyonu gereken durumlarda ya da anestezistin endotrakeal tüp yerleştirmesi sırasında varyasyonların bilinmesi klinik açıdan hayati öneme sahip olabilmektedir. Ayrıca, ayırıcı tanı olarak, erişkin yaşta dahi olsa kronik öksürüğe yol açabilecek olan aksesuar kardiyak boronş düşünülmesi gereken bir olgudur.

\section{REFERANSLAR}

1- Akoğlu, S., Uçan, E.S., Çelik, G., Şener, G., Sevinç, C., Kılınç, O., İtil, O. (2006). Bronkoskopi sırasında saptanan trakeobronşial anomali ve varyasyonlar, Dspace@Hatay Kurumsal Akademik Arşiv. http://openaccess.mku.edu.tr/xmlui/handle/20.500.12483/1040\#sthash.GWV5TADg.dpbs.

2- Taslak, A.S, Durgun, T., Yetim, H., Bayaroğulları, Y., Büyükkarabacak, B. (2013) Trakeal Bronkus: İki Olgu Sunumu. Tracheal Bronchus: Two Case Reports J Kartal Tr 24(3):191-194.

3- Ghaye, B., X. Kos, and R.F. Dondelinger. (1999). Accessory cardiac bronchus: 3D CT demonstration in nine cases. Eur Radiol. 9(1): p. 45-8

4- McGuinness, G., et al. (1993) Accessory cardiac bronchus: CT features and clinical significance. Radiology. 189(2): p. 563-6

5- Jackson, G.D. and J.T. Littleton. (1988). Simultaneous occurrence of anomalous cardiac and tracheal bronchi: a case study. J Thorac Imaging. 3(1): p. 59-60.

6- Remy, J., Remy-Jardin, M., Artaud, D., Fribourg, M. (1998). Multiplanar and three-dimensional reconstruction techniques in CT: Impact on chest diseases. Eur Radiol. 8:335-51

7- Ghaye B, Szapiro D, Fanchamps, JM, Dondelinger, RF. (2001). Congenital bronchial abnormalities revisited. Radiographics. 21: 105-19

8- Ghaye, B., Kos, X., Dondelinger, R.F. (1999) Accessory cardiac bronchus: 3D CT demonstration in nine cases. Eur Radiol,. 9(1): 45-8

9- Barat, M., Konrad, H.R. (1987). Tracheal bronchus. Am J Otolaryngol. 8: 118-22.

10-Harris, J.H.Jr. (1958) The clinical significance of the tracheal bronchus. Am J Roentgenol. 79: 228-34.

11-Read, R., St Cyr, J., Marek,J., et al. (1990). Bronchial anomaly of the right upper lobe. Ann Thorac Surg. 50: 980-1.

12-O’Sullivan, B.P., Frassica, J.J., Rayder, S.M. (1998). Tracheal bronchus: A cause of prolonged atelectasis in intubated children. Chest; 113: 537-40

13-Ghaye, B., Szapiro, D., Fanchamps, J.M., Dondelinger, R.F. (2001). Congenital bronchial abnormalities revisited. Radiographics. 21: 105-19. 